\title{
Platería salmantina del siglo XVIII en la catedral de Ávila. La obra de Luis de Torres y Baeza (1675-1719)
}

\author{
Salamanca's silverwork of the 18th century in the Cathedral of Ávila. \\ The work of Luis de Torres y Baeza (1675-1719)
}

David SÁNCHEZ SÁNCHEZ

Universidad de Salamanca

ORCID: https://orcid.org/0000-0001-9109-9293 / dss@usal.es

DOI: http://dx.doi.org/10.18002/da.v0i18.5879

Recibido: 2-IV-2019

Aceptado: 5-VII-2019

RESUMEN: Durante el siglo XVIII, la ciudad de Salamanca se convirtió en uno de los centros más importantes de la platería española. Algunos de los grandes plateros salmantinos acudieron a trabajar a la catedral de Ávila, llamados principalmente por los obispos y los miembros del cabildo. El primero de ellos fue Luis de Torres y Baeza, que dejó en Ávila sus mejores piezas y cuyo trabajo y biografía son prácticamente desconocidos.

Palabras clave: Platería; Ávila; Catedral; Salamanca; siglo XVIII; Barroco.

ABSTRACT: During the 18th century, the town of Salamanca was one of the most important places of the Spanish silverwork. Some of the greatest silversmiths from there went to work to the cathedral of Ávila, called by the bishops and incumbents of the church. The first of them was Luis de Torres y Baeza, who left in Ávila his better pieces, and whose work and life are still almost unknown.

Keywords: Silverwork; Avila; Cathedral; Salamanca; 18th Century; Baroque.

Con la llegada del siglo XVIII, la catedral de Ávila recuperó la iniciativa por la promoción artística que había perdido durante la mayor parte de la centuria anterior. La crisis económica generalizada por la que atravesó España durante el seiscientos afectó notablemente a la ciudad del Adaja, donde se dejaron sentir con fuerza los efectos de las malas cosechas, la salida de la nobleza local para establecerse en la Corte y la expulsión de la comunidad morisca, cuestiones agravadas por las constantes presiones fiscales de la Corona. La situación supuso un progresivo declive de la producción artística que ha- bía definido a la capital abulense durante el quinientos, en campos como la escultura y la platería, que nunca llegaron a recuperar su esplendor pasado.

Aún con la sombra de las exigencias tributarias que acarrearon algunas campañas bélicas, como el intento de retomar Gibraltar en 1704-1705, o la inestabilidad derivada de la Guerra de Sucesión (1701-1713), los administradores catedralicios abulenses consiguieron mantener la revitalización de los caudales de la fábrica que había comenzado durante los últimos años del siglo XVII. Esto fue posible, entre otros factores, gracias a la 
eficaz gestión de las propiedades censuales y a la venta de bienes y alhajas, especialmente aquellas legadas al tesoro por los obispos precedentes, y que se integraban en el conjunto de ornamentos del pontifical. Concretamente, en el año 1703, don Manuel Pérez de Araciel y Rada, antiguo canónigo y recién nombrado obispo de León, compró una larga lista de piezas de plata, vestiduras y otros enseres, por los que pagó una cantidad superior a los catorce mil reales ${ }^{1}$. Al año siguiente, el cargo por la venta de bienes ascendió a veinte mil reales ${ }^{2}$, y en años posteriores se continuó con la misma dinámica.

En este contexto de saneamiento económico debemos enmarcar algunas de las grandes obras que se llevaron a cabo en el templo abulense durante la primera mitad del siglo XVIII, como la construcción de los nuevos órganos sobre el coro, en 1703 y 1713; la edificación de la nueva sala capitular, obra de Alberto de Churriguera en 1735; y especialmente la reforma integral de la capilla de San Segundo ${ }^{3}$.

Por los registros de cuentas, sabemos que en esa etapa también hubo una creciente actividad en el plano de la platería, un campo especialmente favorecido por dos factores. En primer lugar, obispos y canónigos contribuyeron con capital privado a la adquisición de algunas piezas, que sufragaron en parte o en su totalidad. En segundo lugar, el desembolso económico de la fábrica para la adquisición de nuevas obras de plata se redujo con la entrega de otras de plata vieja, que los canónigos obreros y sacristanes se habían preocupado de preservar durante todo el siglo anterior. Aludimos aquí a la medida preventiva que aprobó el obispo Francisco de Gamarra (prelatura entre 1616

\footnotetext{
${ }^{1}$ Archivo Diocesano de Ávila (ADAV), Sección Archivo Catedralicio, Libro de cuentas de fábrica de 1703, ff. $47 \mathrm{r}-49 \mathrm{v}$.

2 ADAV, Sección Archivo Catedralicio, Libro de cuentas de fábrica de 1704, ff. 46r-47v.

${ }^{3}$ Aunque esta capilla tenía unas rentas independientes de la fábrica catedralicia, su administración dependía directamente de los capitulares del templo.
}

y 1626t) en las constituciones sinodales de 1617, a principios de la crisis, donde se prohibió la venta de cálices y otros ornamentos de la catedral y del resto de iglesias, bajo penas económicas equivalentes al doble de la cantidad obtenida con la venta o enajenación de los bienes ${ }^{4}$. Este decreto estaría en relación con la imposibilidad financiera de adquirir nuevos enseres para el culto divino y tuvo un efecto positivo un siglo después, favoreciendo la renovación del ajuar litúrgico.

Para el estudio de la platería en la catedral de Ávila durante el siglo XVIII, debemos diferenciar entre las obras que salieron de talleres abulenses y las contratadas a plateros de fuera. Como indicábamos unas líneas más arriba, el trabajo de la plata en Ávila no llegó a recuperar la importancia que tuvo durante el siglo XVI y los primeros años del siguiente, con artífices de la talla de Diego y Juan de Alviz, Alejo Martínez, Lucas Hernández o Pedro Hernández, autores de algunas de las piezas más destacadas que aún se conservan ${ }^{5}$. A lo largo del seiscientos, el número de plateros se redujo drásticamente y, según el Catastro de Ensenada, en 1751 el total de maestros activos en Ávila era solamente de seis, más un oficial.

Desde la catedral se contrató el servicio de plateros abulenses para el cargo de maestro oficial del templo, aunque no percibieron un salario por el desempeño de su labor ${ }^{6}$. Durante la primera mitad del siglo XVIII, el puesto lo ocuparon sucesivamente Francis-

${ }^{4}$ ADAV, Sección Archivo Episcopal y Curia, Sinodal de 1617, lib. III, tít. VII, Const. 1.

\footnotetext{
${ }^{5}$ Sobre algunos de estos maestros: Fernando Gu-
} tiérrez Hernández y Lorenzo Martín Sánchez, Pedro Hernández y las mazas del Ayuntamiento de Ávila. Platería abulense del Bajo Renacimiento (Ávila: Ayuntamiento de Ávila, 2003); David Sánchez Sánchez, "El platero abulense Lucas Hernández (c. 1547-1593). Obra y datos biográficos a partir de su testamento", en Estudios de platería. San Eloy 2018, coord. por Jesús Rivas Carmona e I. José García Zapata (Murcia: Universidad de Murcia, 2018), 491-507.

${ }^{6}$ Nombrados anualmente en el cabildo extraordinario celebrado el día de san Cebrián, el 16 de septiembre, junto al resto de oficios y patronatos de la catedral. 
co Rodríguez Mauricio, Lorenzo Vázquez de Mercado y Simón de la Torre, y su labor consistió principalmente en el aderezo y mantenimiento del tesoro, y la elaboración ocasional de piezas que podríamos definir como de uso ordinario, esto es, vinajeras con sus platillos, hisopos, pequeñas cruces de altar y navetas. Su trabajo creativo fue mayor en la capilla de San Segundo, de acuerdo a la renovación ornamental de ese espacio. Allí realizaron lámparas, incensarios y candeleros, además de las consabidas labores de limpieza y conservación del ajuar eucarístico propio.

Las limitaciones de los obradores abulenses y la notoriedad que había adquirido la platería de otras ciudades, provocaron que los grandes proyectos se encargasen a artífices foráneos. Por encima de las piezas procedentes de talleres de Madrid, Córdoba o Barcelona ${ }^{7}$, destacan el número de ellas que salieron de los talleres salmantinos de Luis de Torres y Baeza, Manuel García Crespo, Juan Manuel Sanz de Velasco o Manuel Pérez Espinosa.

La platería de Salamanca había comenzado su momento álgido en la segunda mitad del siglo XVII y su importancia se mantuvo a lo largo del $\mathrm{XVIII}^{8}$. La riqueza y variedad de las composiciones de platería salmantina podría ser la justificación más evidente para que los canónigos de la catedral de Ávila fijasen su interés en los talleres de la capital del Tormes, donde por entonces vivieron -según el Catastro de Ensenada-cuarenta maestros plateros, veinticuatro oficiales y veintisiete aprendices, números que convertían a la ciudad en uno de los re-

\footnotetext{
${ }^{7}$ Fernando Gutiérrez Hernández y Lorenzo Martín Sánchez, "Luces y sombras en la platería de la Catedral de Ávila (1700-1800)", en Estudios de platería. San Eloy 2007, coord. por Jesús Rivas Carmona (Murcia: Universidad de Murcia, 2007), 157-186.

${ }^{8}$ Manuel Pérez Hernández, Orfebrería religiosa en la Diócesis de Salamanca. Siglos XV al XIX (Salamanca: Diputación de Salamanca), 157.
}

ferentes de la platería española del momento junto a Madrid y Córdoba9 .

\section{DATOS BIOGRÁFICOS DE LUIS DE TORRES Y BAEZA}

El primero de los plateros salmantinos en acudir a la llamada de los administradores catedralicios abulenses fue Luis de Torres y Baeza (1675-1719). Se trata de un platero poco conocido que, consideramos, merece un estudio pormenorizado de su vida y obra, atento a las características que presentan sus trabajos y a la relevancia del lugar para el que fueron concertados. Gracias a la documentación localizada, sabemos que en la catedral de Ávila realizó varias obras: una urna para las reliquias de san Segundo, una araña o lámpara para alumbrar el Sacramento en el Monumento de Jueves Santo y durante la octava del Corpus Christi, un arca con su peana destinada a la renovación del Santísimo y otras dos lámparas menores para la capilla de San Segundo.

Existen dos motivos principales por los que su figura ha pasado inadvertida. El primero es la falta de un estudio crítico de la platería catedralicia abulense ${ }^{10}$; el segundo es la ausencia de ejemplos artísticos atribuibles al maestro en su ciudad de procedencia, Salamanca. En esta capital y su demarcación diocesana, los principales estudios de platería religiosa corresponden al profesor Manuel Pérez Hernández ${ }^{11}$, aunque las aporta-

${ }^{9}$ J. Carlos Brasas Egido. La platería vallisoletana y su difusión (Valladolid: Institución Cultural Simancas, 1981), 322-323.

${ }^{10}$ Julián Blázquez Chamorro, difunto canónigo catedralicio, dedicó algunas publicaciones al estudio de la platería abulense, sin embargo, su encomiable labor carece de un verdadero análisis del trabajo de la plata en Ávila y comete importantes errores de datación y atribución. Sus aportaciones, en cambio, incorporan interesantes referencias documentales y su trabajo sobre la platería catedralicia fue el primer catálogo sobre este género artístico en Ávila. Julián Blázquez Chamorro, La platería de la catedral de Ávila (Ávila: Cabildo Catedral de Ávila, 2003).

${ }^{11}$ Pérez Hernández, Orfebrería...; algunas referencias sobre el platero en: Manuel Pérez Hernández, “El 
ciones publicadas acerca de nuestro platero se limitan a unas pocas notas, habida cuenta de la inexistencia de piezas relacionadas con él ${ }^{12}$.

Luis era hijo de Roque de Torres y Baeza, mercader de paños, y de Susana de Huebra, y fue bautizado el 29 de agosto de 1675 en la parroquia de San Martín de Tours de la capital charra ${ }^{13}$. Tuvo dos hermanas, Rosa y Antonia, casadas con sendos maestros plateros salmantinos, Fernando Cosío Bonal y Francisco de Ágreda ${ }^{14}$, cuestión que explica los estrechos lazos de unión entre la familia de Luis y el colectivo de plateros. No conocemos datos sobre su etapa de formación, tales como el nombre de su mentor o el momento en que alcanzó el grado de maestría. La siguiente referencia documental data del año 1701, cuando fue elegido para desempeñar el cargo de mayordomo de la cofradía de San Eloy, por lo que presuponemos que ya ejercía como maestro platero ${ }^{15}$. En esta congregación también ejerció como diputado de mayordomo durante el año 1709/1710 y como diputado de cofradía en 1717/1718 ${ }^{16}$. También fue nombrado mayordomo de la cofradía devocional de Nuestra Señora de la Paz en $1719^{17}$.

tesoro de la catedral de Ávila. Liturgia y magnificencia", en La catedral de Ávila. Nueve siglos de historia y arte, coord. por René Jesús Payo Hernanz y Jesús M. Parrado del Olmo (Burgos: Promecal, 2014), 618, nota 104.

${ }^{12}$ Agradecemos a Manuel Pérez Hernández habernos facilitado los datos biográficos sobre Luis de Torres y Baeza que se incorporan en este estudio, en su mayoría inéditos.

${ }^{13}$ Archivo Diocesano de Salamanca (ADSA), Libro de Bautismos de la parroquia de San Martín de 1639 y ss., f. $262 \mathrm{v}$

${ }^{14}$ Sobre el segundo de los dos, vid. Pérez Hernández, orfebrería...,171-173

${ }^{15}$ Archivo de la Escuela de Nobles y Bellas Artes de San Eloy de Salamanca (ASESA), Libro de acuerdos de la cofradía de San Eloy (1608-1775), ff. 68r-v.

${ }^{16}$ ASESA, Libro de acuerdos de la cofradía de San Eloy (1608-1775), ff. 75r y 90r.

${ }^{17}$ ADSA, Libro de juntas y acuerdos de la cofradía de Nuestra Señora de la Paz (1566-1740), s. f.
En cuanto a su vida personal, contrajo matrimonio hacia 1701 con Isabel María Sáez del Corral, según una declaración firmada dos años después junto a otros plateros -Antonio López Lozano, Lázaro de Olondriz y Diego del Campo-, donde declaraba tener mucha familia a su cargo, aunque no tenemos información acerca de posibles hijos ${ }^{18}$.

Las noticias sobre su labor profesional en Salamanca son escasas y principalmente vinculadas a su relación con algunos compañeros. En diciembre de 1701 otorgó poder ante notario, junto al platero José Saurina, para que este pudiera cobrar ciertas cantidades que se le adeudaban ${ }^{19}$. Es mencionado en el testamento de Antonio Luis de la Cruz, firmado en julio de 1716, por estar en posesión de algunas piezas de plata, propiedad de aquel maestro, que Luis había ido a vender a Segovia ${ }^{20}$. Unos meses después, el 9 de agosto de 1717, otorgó las fianzas requeridas, junto a Gerónimo de Ágreda, sobre las andas de plata de la iglesia de Santa María la Mayor de Ledesma, obra realizada por su cuñado Francisco de Ágreda ${ }^{21}$. Conocemos el nombre de un aprendiz, José de Morales, que murió durante su etapa de formación ${ }^{22}$. En los documentos localizados en Salamanca solo se menciona una pieza salida de su taller, una fuente de plata para la iglesia de san Julián, por la que percibió 1.430 reales de vellón el 9 de marzo de $1712^{23}$.

Murió el 23 de junio de 1719, a la edad de 43 años, según se recoge en el inventario de bienes realizado tras su fallecimiento. La plata y utensilios propios de su oficio fueron tasados el día 4 de julio de ese año por

${ }^{18}$ Archivo Histórico Provincial de Salamanca (AHPSA), Protocolo 4.900, ff. 139r-142r.

${ }^{19}$ AHPSA, Protocolo 4.125, ff. 67r-v.

${ }^{20}$ AHPSA, Protocolo 4.133, f. 560v.

${ }^{21}$ AHPSA, Protocolo 5.731. f. 577r.

${ }^{22}$ Los gastos derivados de su entierro en: ASESA, Libro de cuentas de la cofradía de San Eloy (1701-1794), s. f.

${ }^{23}$ ADSA, Libro de cuentas de la parroquia de san Julián (1707-1754), f. 48r. 
Manuel García Crespo ${ }^{24}$. En los libros de cuentas de la cofradía de plateros figura el descargo por su entierro, como miembro que fue de esta congregación religiosa de carácter profesional ${ }^{25}$.

No conocemos su marca de platero ya que, como hemos señalado, en Salamanca no se conservan ejemplos de su trabajo y las piezas de Ávila no presentan distintivos de autoría, aunque gracias a la documentación podemos constatar que fueron obras de Luis de Torres y Baeza, así como la fecha de su realización. (Fig. 1)

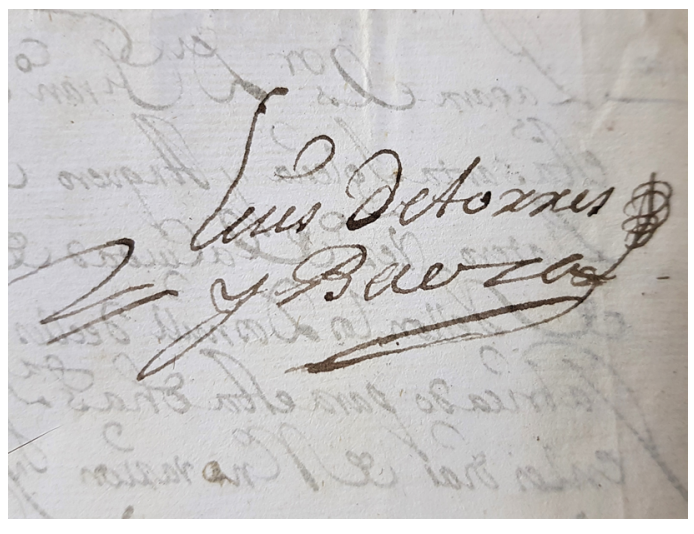

- Fig. 1: Firma de Luis de Torres y Baeza. Libramiento fechado el 4 de julio de 1713. Archivo Diocesano de Ávila. Sección Archivo Catedralicio. Caja 16/1/7, legajo 8. Fotografía del autor.

\section{LA URNA-RELICARIO DE SAN SE- GUNDO}

Los escasos comentarios publicados hasta el momento sobre este maestro se han centrado en la única obra de la que se conocía documentación, la urna de las reliquias de san Segundo, en la catedral de Ávila. Este trabajo se recogió, por primera vez, en el estudio artístico y crono-constructivo de la capilla dedicada al patrón abulense, realizado por Luis Cervera Vera, en $1952^{26}$. Del impor-

${ }^{24}$ AHPSA, Protocolo 3.055, ff. 651r-706r

${ }^{25}$ ASESA, Libro de cuentas de la cofradía de San Eloy (1701-1794), s. f.

${ }^{26}$ Luis Cervera Vera, "La Capilla de San Segundo en la Catedral de Ávila", Boletín de la Sociedad Española de Excursiones, año LVI (1959), 222-223. Manuel Gó- tante conjunto de piezas de plata realizado para este lugar en el siglo XVIII, el autor únicamente cita la urna, y ofrece algunos datos extraídos de los libros de cuentas, como el peso, las cantidades percibidas por el platero y el momento de finalización de la obra.

La información fue ampliada por José Carlos Brasas en 1975 ${ }^{27}$. Indica que la urna contiene el punzón del marcador salmantino Francisco Villarroel (VILLA/ROEL), que ejerció el marcaje en Salamanca entre 1707 y $1749^{28}$. También incluye la transcripción de los pagos que había mencionado con anterioridad Cervera Vera. El primero corresponde al año 1710 y consistió en un adelanto de 8.572 reales de vellón "por la quenta del coste que tubiere la urna que está haciendo para colocar el cuerpo del glorioso san Segundo" ${ }^{29}$. El otro documento transcrito contiene el ajuste final de la cuenta, con el registro de pago de 22.808 reales, que junto a los de la cuenta anterior sumaron un total de 31.380 reales de vellón por el total de la urna. Pesó 1.092 onzas, que por valor de 15 reales cada onza, resultaron un total de 16.380 reales por el precio de la plata y 15.000 reales en que se acordó la hechura ${ }^{30}$.

Estos mismos datos los repitieron Fernando Gutiérrez y Lorenzo Martín en una publicación dedicada a algunos ejemplos de

mez-Moreno fue el primero en mencionar la urna, aunque en la redacción original de su catálogo monumental, del año 1900, la atribuye al platero Manuel García Crespo, un error corregido en la edición de Áurea de la Morena y Teresa Pérez Higuera, quienes remiten a las aportaciones de Cervera Vera. Véase: Manuel Gómez-Moreno, Catálogo monumental de la provincia de Ávila (Ávila: Institución Gran Duque de Alba, 1983), 128.

${ }^{27}$ José Carlos Brasas Egido, “Aportaciones al estudio de la platería barroca española" Boletín del Seminario de Estudios de Arte y Arqueología, nº 40-41 (1975), 437.

${ }^{28}$ Pérez Hernández, Orfebrería..., 45.

${ }^{29}$ ADAV, Sección Archivo Catedralicio, Fondo Capilla de San Segundo, Libro de cuentas de fábrica (16911762) año 1710, s. f..

${ }^{30}$ ADAV, Sección Archivo Catedralicio, Fondo Capilla de San Segundo, Libro de cuentas de fábrica (16911762) año 1713 , s. f. 
la platería de la catedral de Ávila del siglo $\mathrm{XVIII}^{31}$. El último en acercarse a la urna fue Pérez Hernández en un estudio sobre el tesoro catedralicio y su evolución histórica a partir de las piezas que se conservan, pero no incorporó nuevos datos u observaciones $^{32}$.

La base de nuestra aportación al respecto de la urna de las reliquias de san Segundo consiste en incorporar nuevas referencias documentales sobre la finalización de la pieza, poner en valor la obra a partir de sus particularidades artísticas -apenas descritas hasta ahora-, llamar la atención sobre la importancia que tenía este encargo para el cabildo catedralicio y destacar la relevancia de su promotor.

La primera de las aportaciones documentales que incluimos aparece en los libros de actas capitulares de 1713, concretamente el miércoles 25 de enero, momento en que se anuncia la llegada de la urna para colocar las reliquias, según el acta rotulada al margen "sobre la colocación del cuerpo de señor san Segundo en la nueva urna"33.

“El señor doctoral dio quenta haberse conducido a esta ciudad la nueva urna de plata que havía hecho fabricar en Salamanca para colocar el cuerpo de señor san Segundo, patrón de esta Sancta Iglesia, y que respecto de ser alaja de buena hechura y crecido valor, convendría el cabildo se sirviese determinar se ponga de forma que se logre su vista, desponiendo para ello y para maior culto del Santo Patrono se adorne dicha capilla en el mejor modo que sea posible, y entendido por el cabildo se mandó llamar para el primero (capítulo) para determinar la forma en que se ha de poner dicha urna y tratar sobre lo que será más conveniente para que se dé el mayor culto al señor san Segundo".

\footnotetext{
${ }^{31}$ Martín Sánchez y Fernando Gutiérrez Hernández, “Luces y sombras...", 161.

32 Pérez Hernández, "El tesoro...", 470.

${ }^{33} \mathrm{ADAV}$, Secc. Archivo Catedralicio, Actas capitulares de 1713 , f. 11 r.
}

Además de este fragmento, para conocer la relevancia que se concedió a la adquisición de la urna es necesario retroceder hasta el siglo XVI. En 1519, en una ermita románica junto al río Adaja, se descubrieron las supuestas reliquias del primer obispo de Ávila, san Segundo, uno de los varones apostólicos enviados por san Pedro y san Pablo a evangelizar la Hispania romana. Pronto el cabildo quiso trasladar los restos del santo hasta el primer templo, aunque la iniciativa se vio frenada en varias ocasiones por el fervor popular y por la oposición de las cofradías devocionales de esa ermita, dedicada originariamente a san Sebastián. Durante la prelatura del obispo don Jerónimo Manrique de Lara (1591-1595) finalmente se materializó el traslado de las reliquias a la catedral, y el obispo dotó la construcción de una capilla anexionada a la cabecera del templo, donde se habrían de custodiar ${ }^{34}$.

El cuerpo del primer obispo abulense se colocó en una urna de madera forrada de damasco rojo, citada en los inventarios. La única alhaja que se encargó para dar culto al santo fue un relicario de plata, de pequeño formato, destinado a exhibir un hueso, que se concertó con el platero catedralicio Juan de Alviz en 1595, acaso por la incapacidad económica para adquirir un expositor de mayor formato y adecuadamente ornamentado.

El proyecto de la urna-relicario de plata en el siglo XVIII se debe integrar en la reforma decorativa de la capilla de San Segundo, que comenzó por la adquisición de esta pie$\mathrm{za}$, y considerarse como un hito devocional y artístico. Así se manifiesta en el interés que demostró el cabildo, según las actas capitulares, por colocar la urna en un lugar preeminente, atendiendo a su valor integral.

A partir del texto transcrito, destacamos la figura del canónigo doctoral de la catedral, por tratase del impulsor del encargo

\footnotetext{
${ }^{34}$ Antonio de Cianca, Historia de la vida, invención, milagros y translación de S. Segundo, primero obispo de Ávila (Madrid: Imprenta de Luis Sánchez, 1595).
} 
y que, durante esos años, también ejercía como patrono -entendido como administrador- de la capilla de San Segundo. Se trata de don Amador Merino Malaguilla (16771755), que ostentó el cargo de doctoral desde el año 1705 hasta su nombramiento como maestrescuela de la catedral de Salamanca en 1722, para ser designado obispo de Badajoz en 1730, prelatura que ocupó hasta su fallecimiento ${ }^{35}$.

En nuestro caso, la importancia de este canónigo radica en su labor de promotor artístico, ya que podríamos ver en él al principal incitador para la llegada de artistas salmantinos a la catedral de Ávila. Durante el desempeño de su labor como patrono de San Segundo, entre los años 1710 y 1722, se contrató el retablo-baldaquino de Joaquín de Churriguera para alojar la urna con las reliquias, terminado en $1716^{36} ; \mathrm{y}$, además del mecenazgo que ejerció con Luis de Torres y Baeza, también fue responsable de algunas obras realizadas en la catedral abulense por el platero Manuel García Crespo, sobre las que no hablaremos aquí, al ser un tema que requiere un estudio independiente.

Coincidiendo con la finalización del tabernáculo, se encargó a Torres y Baeza que rematase la urna con unas garras de león para asentarla, un complemento que no estaba incluido en el diseño original y al que no aluden las publicaciones mencionadas. El día 28 de noviembre de 1716 se libraron al platero 250 reales de vellón que se le adeudaban por el valor de las dichas garras, que pesaron cuarenta onzas de plata. El pago también incluía el coste de unas bolas de bronce situadas en los apoyos ${ }^{37}$.

\footnotetext{
${ }^{35}$ La página web de la Real Academia de la Historia ofrece algunos datos biográficos sobre este personaje: enlace web.

${ }^{36}$ ADAV, Sección Archivo Catedralicio, Libro de actas capitulares de 1714, ff. $48 \mathrm{r}-48 \mathrm{v}$.

${ }^{37}$ ADAV, Sección Archivo Catedralicio, Fondo Capilla de San Segundo, Libro de cuentas de fábrica (16911762), año 1716, s. f.
}

El inventario de bienes y alhajas de la capilla del año 1737 contiene una breve descripción de la pieza, donde se menciona a Luis de Torres y Baeza como su autor, además de repetir el coste que tuvo la obra y su peso final. Es más detallada la información que aparece en el inventario de $1750^{38}$ :

“Una urna de plata con quatro pies en forma de uñas de león i en cada pie un serafín, y en lo alto de ella once ángeles de cuerpo entero teniendo varios atributos del santo, quatro vidrios de christal y a los cantos de ellos quatro serafines y a las quatro caras quatro escudos, los dos de las armas del cavildo, otro de las del señor fundador y otro en que se está gravado [sic] el martirio del santo. Estos, los serafines y ángeles, están dorados a eszepzión de los de abajo, y sobre dichos escudos hai quatro serafines dorados; en la qual dicha urna se venera el cuerpo del glorioso san Segundo, metido en un arca forrada de terziopelo encarnado y galoneada con galón de oro fino".

El relicario responde a la tipología de urna sepulcral, presenta un perfil tronco piramidal invertido y está abierto en sus cuatro frentes con vidrios, cubiertos con terciopelo carmesí que oculta el contenido de la urna. La tapa es igualmente piramidal truncada, de caras cóncavas y aperturas en forma de óculos. (Fig. 2)

De los once ángeles sobredorados de bulto redondo, ocho se sitúan en las esquinas -cuatro las de la base y otros cuatro en las de la tapa-, todos ellos presentan unas actitudes dinámicas e inestables y sujetan ramos florales. Tres ángeles más se colocan en la parte superior de la tapa, sustentando los atributos episcopales, un báculo y una mitra ricamente ornamentada a base de motivos repujados. Otras ocho cabezas doradas de serafines se distribuyen por el resto de la

\footnotetext{
${ }^{38}$ Titulado: Inventario de las alajas y todo lo demás perteneciente a la capilla y capellanías del señor San Segundo, nuestro patrón. Contiene varios inventarios de bienes desde el año 1641 hasta 1909. ADAV, Sección Archivo Catedralicio, Fondo Capilla de San Segundo, Inventario de bienes y alhajas (1641-1909), ff. 70r-70v.
} 


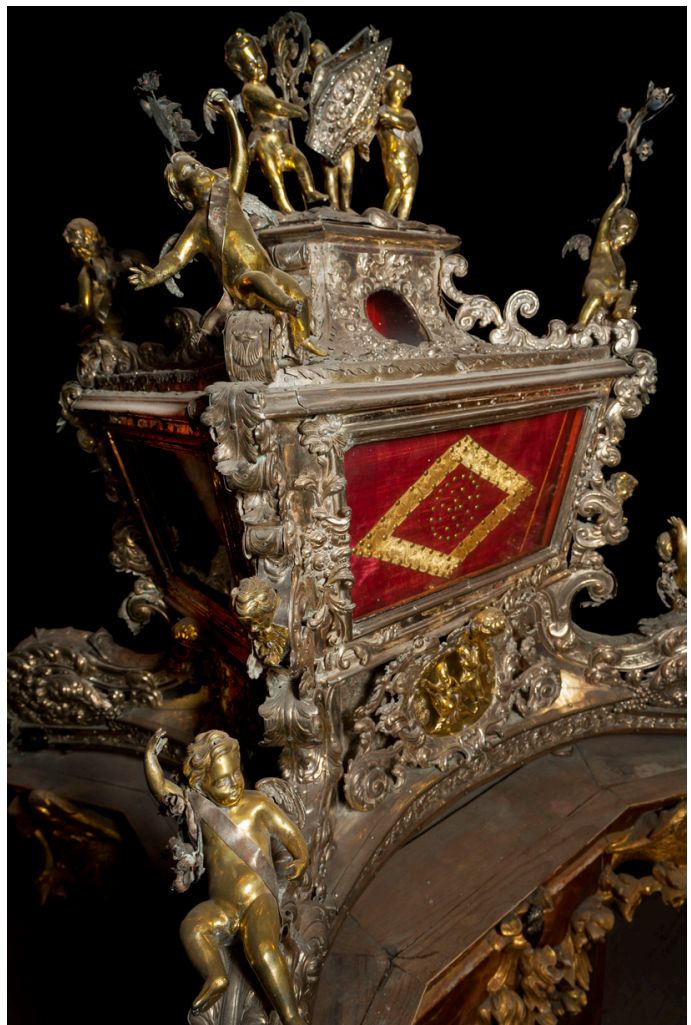

- Fig. 2: Luis de Torres y Baeza. Urna-relicario de San Segundo, 1713. Capilla de San Segundo de la catedral de Ávila. Fotografía de Alberto Rodrigo / Ediciones Promecal.

estructura, cuatro en las aristas de la caja y las otras cuatro coronando los medallones que aparecen en los frentes de la base, que contienen los escudos y relieves descritos $\operatorname{arriba}^{39}$.

La tendencia marcada por los hermanos Churriguera, en cuanto a la desvinculación de la norma clásica, se traspone a la obra de plata a través del artificio arquitectural y el enmascaramiento de la estructura con abundante decoración a base de tarjetones con acantos, volutas y roleos ${ }^{40}$. Algunas conco-

${ }^{39}$ Dada la imposibilidad de acceder a la urna, situada en el interior del tabernáculo, no podemos ofrecer sus medidas.

${ }^{40}$ Manuel García Crespo protagoniza algunos ejemplos de la interdisciplinariedad del trabajo en plata y las influencias recibidas por otros artistas. En las andas de la cofradía del Sacramento de Medina de Rioseco siguió el diseño de Pedro de Sierra; y en las andas de la custodia del Corpus Christi de la catedral de Salamanca, fue Alberto de Churriguera quien dio las trazas en 1728. mitancias ornamentales entre el tabernáculo y el relicario remiten al uso de fuentes gráficas comunes y un vocabulario decorativo análogo, propio del pleno barroco. Así se aprecia en los mensulones de las esquinas de la base de la urna, que tienen su equivalente en las esquinas del primer cuerpo del retablo, sobre los que se colocan esculturas de santos; o la repetición del modelo de los putti en la mitad superior del tabernáculo, sujetando coronas florales y cornucopias, en posiciones inestables.

Una vez se entregó la urna y se depositaron en ella las reliquias, se exhibió en su capilla durante más de un año. Después, para permitir la instalación del nuevo retablo, el cabildo decidió situarla provisionalmente en la capilla de la Piedad, "con el adorno que fuera necesario". No fue hasta 1728 cuando la urna con las reliquias volvió a su capilla, para colocarse en el lugar al que estaba destinada, donde aún se expone. (Fig. 3)

\section{LÁMPARA DE PLATA PARA EL MO- NUMENTO Y LA OCTAVA DEL COR- PUS}

La siguiente referencia que tenemos de Luis de Torres y Baeza en relación con la catedral de Ávila es un año posterior a la contratación de la urna, data del 3 de julio de 1711, en el acta capitular de ese día ${ }^{41}$ :

"El señor doctoral dijo que, hallándose en esta çiudad un platero de la de Salamanca, quien traýa una araña de plata de más de quinientas onzas de peso y de buena hechura, y pareziendo a dicho señor que en ella havía de hazer gran combeniençia y ser alaja mui propia para esta Santa Iglesia, havía tratado sobre su compra en la forma que expresó al cabildo, a quien lo participó

Manuel Pérez Hernández "Sobre la interdisciplinariedad de las artes. Manuel García Crespo y el barroco salmantino", en Estudios de platería. San Eloy 2007, coord. por Jesús Rivas Carmona (Murcia: Universidad de Murcia, 2007), 285-286.

${ }^{41}$ ADAV, Sección Archivo Catedralicio, Libro de actas capitulares de 1711, ff. 53r-53v. 


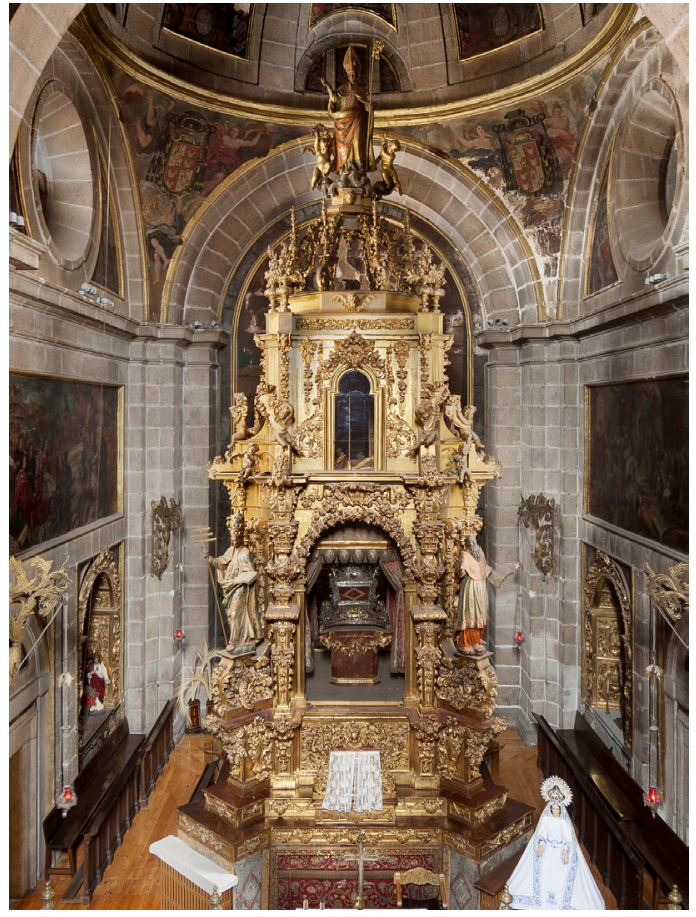

- Fig. 3: Joaquín de Churriguera. Retablo-baldaquino de la capilla de San Segundo de la catedral de Ávila, 1716. Fotografía de Alberto Rodrigo / Ediciones Promecal.

para si gustase entrar en ella. Y entendido por dichos señores y haviéndose ablado y conferido en razón de ello, se dio comisión a dicho señor doctoral para que si en la forma que lleva entendido pudiere ajustar la referida araña, lo execute y con la condiçión de haverse de dar para en parte del peso de ella la plata que se reconoziere no ser de uso en esta Santa Iglesia"

Sobre esta nota debemos hacer una serie de apreciaciones. En primer lugar, volvemos a ver al canónigo doctoral Amador Merino Malaguilla como responsable o intermediario para la adquisición de la pieza, aun cuando la administración de los bienes y alhajas del tesoro correspondía tradicionalmente al canónigo obrero o al sacristán mayor.

En segundo lugar, llama la atención que el platero se personase en Ávila con una obra terminada, sin la aparente certeza de un comprador. Podríamos especular con dos teorías: que la araña no fuese una creación de Torres y Baeza, sino que el platero estuviera ejerciendo como intermediario de un tercero, al igual que ocurrió en 1716, cuando acudió a Segovia a vender algunas obras de Antonio Luis de la Cruz; o que Merino Malaguilla hubiera acordado previamente la compra de la pieza de su propio peculio, y que finalmente hiciera partícipe al cabildo para "si gustase entrar en ella", opción por la que nos inclinamos, dada la relación que pareció existir entre platero y canónigo.

Aunque no figura el nombre de Luis de Torres y Baeza en el acta capitular, sabemos que el platero al que se refiere el texto era él, gracias al contenido de las cuentas de fábrica de ese año, donde se recoge el coste de la araña de plata. Se indica que dos días después de la propuesta, se pagaron al platero vecino de Salamanca la cantidad de 10.140 reales de vellón por el valor de las 536 onzas que pesó la lámpara, a 15 reales cada onza, y 1.100 reales en que se tasó la hechura ${ }^{42}$.

En el inventario de bienes de la catedral de 1750, la lámpara, que no se conserva, se describe como una "araña de plata de filigrana con doze mecheros, que sirve para el Monumento y octava del Corpus. Pesa quinientas y treinta y seis honzas $(\ldots)^{\prime \prime 4}$. Además de la descripción, nos interesamos por el uso que se daba a la pieza, al colocarla en la nueva estructura para el Monumento de Jueves Santo que, coincidiendo con la adquisición de la araña, estaba diseñando para la catedral el pintor y tracista madrileño Francisco de Llamas ${ }^{44}$. También se utilizaría para iluminar el trono de plata donde se velaba el Santísimo Sacramento durante la octava del Corpus Christi.

\footnotetext{
${ }^{42}$ ADAV, Sección Archivo Catedralicio, Libro de cuentas de fábrica de 1711, f. 37r.

${ }^{43} \mathrm{ADAV}$, Sección Archivo Catedralicio, Inventario de bienes y alhajas (1750), f. 2r.

${ }^{44}$ Algunos datos biográficos sobre este maestro en: Ángel Aterido Fernández, El final del Siglo de Oro: la pintura en Madrid en el cambio dinástico 1685-1726 (Madrid: CSIC - Coll \& Cortés, 2015), 331-332.
} 
ARQUETA Y PEANA PARA LA RENOVACIÓN DEL SACRAMENTO

Julián Blázquez Chamorro, en el catálogo sobre la platería de la catedral abulense, atribuyó a la mano de Luis de Torres y Baeza un arca o arqueta que se expone en el museo catedralicio, aunque no aportó mayores datos y erró ligeramente en su datación al considerarla una obra de 1717. Lo mismo ocurre con una peana, que en este caso no se exhibe, y que fechó en $1720^{45}$.

La información que hemos localizado en el Archivo Diocesano de Ávila confirma que ambas piezas forman parte de un proyecto unitario, realizado por Luis de Torres y Baeza entre 1713 y 1714.

En esta ocasión nada se dice en las actas capitulares sobre su adquisición, aunque sí aparecen referencias en los libros de fábrica. La primera de las dos piezas en terminarse fue la peana. El cuatro de julio de 1713 se libraron a Luis de Torres y Baeza 2.120 reales de vellón, por el valor de la obra terminada, que pesó 193 onzas $^{46}$. De la cantidad percibida, 2.000 reales correspondían a la hechura, ya que la mayor parte de la plata empleada en la nueva obra fue entregada por la catedral "en diferentes alajas que no eran de uso en esta Santa Iglesia". Solo se tuvieron que añadir ocho onzas de plata, por valor de 120 reales. En el precio de la hechura también se incluía el dorado de algunas figuras ${ }^{47}$.

En la misma cuenta se especifica el uso que habría de tener: "ha de servir para poner el arca en los días de renovación y colocar las reliquias que ay en el sagrario ${ }^{48}$, en los días que de ellas se rezare".

${ }^{45}$ Blázquez Chamorro, Platería... 94 y 121.

46 ADAV, Sección Archivo Catedralicio, Libro de cuentas de fábrica (1713), f. $35 \mathrm{v}$.

${ }^{47}$ La misma información se contiene en la carta de libramiento correspondiente a la peana, firmada por el tesorero catedralicio Francisco de Larrea y por el propio platero. ADAV, Sección Archivo Catedralicio, c. 16/1/7, leg. 8

${ }^{48}$ El sagrario, capilla del sagrario o sala del tesoro, es una pequeña estancia del siglo XIV destinada a
A renglón seguido, consta un primer pago por la urna, que por entonces aún se estaba realizando. Se adelantaron, del pago final, 1.200 reales de vellón "de lo que importare el peso y hechura de un arca de plata" $^{\prime 49}$. En las cuentas de fábrica del año siguiente figura la liquidación. El platero percibió 4.585 reales de vellón, que sumados a los de la cuenta anterior montan 5.785 reales por el valor total de la arqueta. De ellos 2.985 correspondían a las 199 onzas de plata que tuvo que añadir a las otras 92 que le había entregado la catedral en plata vieja; y 2.800 reales eran relativos al precio fijado por la hechura ${ }^{50}$. En este apunte también consta que debería servir tanto para la renovación del Sacramento en el altar mayor, como para el Monumento del Jueves Santo, completando así la estructura diseñada por Francisco de Llamas junto a la mencionada araña de plata.

En el inventario de bienes de la catedral de 1750 aparecen ambas piezas, y se aporta su peso y coste, pero no una descripción detallada. La estructura de la peana recuerda una basa columnaria, formada por tres molduras superpuestas, con una anchura máxima de 44 centímetros en la moldura central y una altura de 18 centímetros. La base o plinto es de perfil prismático, los frentes decorados con abundantes motivos vegetales y las esquinas redondeadas, donde surgen cabezas doradas de ángeles (falta una). La segunda moldura, a modo de toro sobre una escocia lisa, recibe decoración vegetal, con frutos bulbosos y flores, y en el centro de cada cara

la custodia de los ornamentos, alhajas de plata y algunas reliquias de la catedral. Con el paso de los siglos también sirvió como sacristía de beneficiados y puntualmente se celebraron algunos cabildos. Desde que la antigua sala capitular -capilla de San Bernabé- adquirió las funciones de sacristía principal, la capilla del sagrario comenzó a servir como antesacristía. Hoy se integra en las dependencias del Museo Catedralicio.

${ }^{49}$ También se conserva el libramiento firmado por el tesorero y por el platero, fechado el 7 de julio de 1713. ADAV, Secc. Archivo Catedralicio, c. 16/1/7, leg. 8

${ }^{50}$ ADAV, Sección Archivo Catedralicio, Libro de cuentas de fábrica de 1714 , ff. 35v-36r. 
vuelven a aparecer las cabezas aladas doradas. La moldura superior es lisa y de escaso desarrollo, cuadrada, con esquinas matadas y, por única decoración, incluye un tarjetón situado en el centro de cada lado, que continúa en la parte de la escocia ${ }^{51}$.

La arqueta tiene una altura total de 37 centímetros, por una anchura de 32 centímetros entre las patas y de $26^{\prime} 5$ centímetros en la caja ${ }^{52}$. Se apoya sobre cuatro ménsulas con forma de volutas que se proyectan en vertical y discurren por las aristas del arca, decoradas con acantos, emulando los principios de la ornamentación arquitectónica contemporánea. Cada uno de los cuatro frentes tiene la misma decoración en chapa de plata, que cubre la estructura. Sobre un fondo de hojas y frutos surgen dos ángeles dorados en posición contorsionada, que sujetan un medallón donde aparecen los atributos eucarísticos que anuncian la finalidad de la pieza: espigas, racimos de uvas y hojas de vid cinceladas y doradas. Remata cada frente una cabeza de serafín dorada.

La tapa repite un diseño similar al del relicario de san Segundo. Tiene forma de pirámide truncada de lados cóncavos, decorados con motivos vegetales cincelados y parejas de festones florales unidos mediante un remate flordelisado en el centro de cada cara. De las aristas nacen ménsulas de perfil mixtilíneo y decoraciones de hojas, que se proyectan hacia el centro para formar una suerte de pináculo rematado con un florón, conseguido a base de láminas e hilos de plata. (Fig. 4)

\section{LÁMPARAS PARA LA CAPILLA DE SAN SEGUNDO}

Tras la entrega de la arqueta y antes de recibir el encargo de las garras de león para la urna de san Segundo, Luis de Torres y Baeza realizó otro trabajo en la catedral de

\footnotetext{
${ }^{51}$ Algunas de estas ornamentaciones se han perdido o están seccionadas.

${ }^{52}$ Una breve descripción del arca, sin incluir la peana, en: Pérez Hernández, El tesoro..., 464.
}

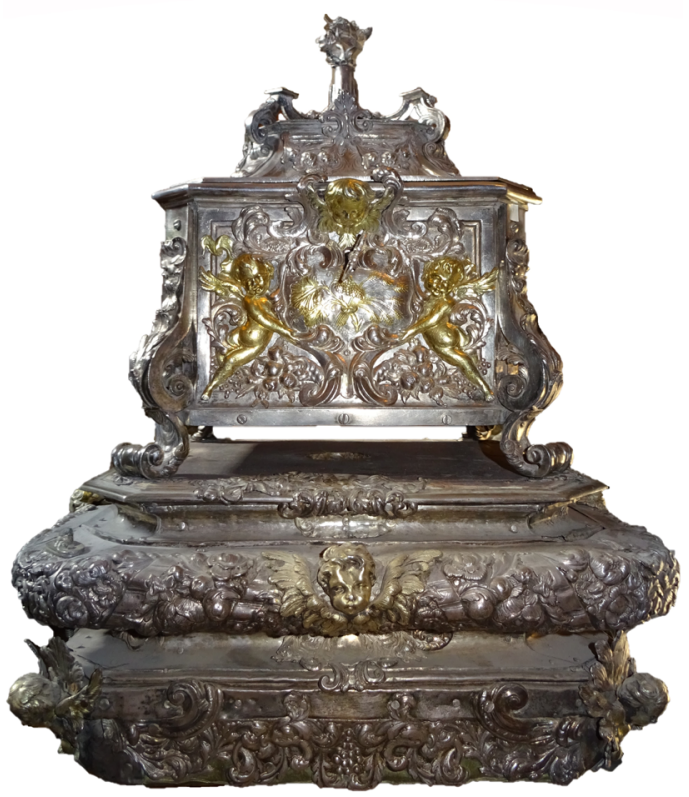

- Fig. 4: Luis de Torres y Baeza. Arqueta y peana para la renovación del Sacramento y el Monumento de Jueves Santo, 1713/1714. Catedral de Ávila. Fotografía del autor.

Ávila, también para la capilla del santo, a cuyo patrono, Amador Merino Malaguilla, deberíamos nuevamente la contratación del platero salmantino. En esta ocasión se le encargaron dos lámparas, que pesaron 113 onzas de plata nueva, añadidas a las 296 onzas de una lámpara vieja que se le entregó. En total, el día 13 de agosto de 1715, recibió 2.695 reales de vellón, de los cuales 1.000 correspondían a la hechura ${ }^{53}$.

Por haber desaparecido, nos remitimos de nuevo al inventario de bienes y alhajas de la capilla para conocer algunos detalles acerca de estas piezas ${ }^{54}$ :

“Dos lámparas con quatro cadenas de eslavones gruesos con sus labores, y en las copas diferentes cartelas, ambas compañe-

${ }^{53} \mathrm{ADAV}$, Sección Archivo Catedralicio, Fondo Capilla de San Segundo, Libro de cuentas de fábrica (16911762), año 1715 , s. f.

${ }^{54}$ ADAV, Sección Archivo Catedralicio, Fondo Capilla de San Segundo, Inventario de bienes y alhajas (1641-1909), f. 41v. 
ras, y de una misma hechura, pessan quatrocientas y nuebe onzas".

“Otras dos lámparas de plata compañeras y de la misma echura que las dos antecedentes, las cuales hizieron en esta ciudad Carlos Bermúdez y Juan Canales, plateros, vezinos de ella, ni más ni menos que las dichas antecedentes que hizo Luis de Torres y Baeza, vezino de Salamanca (...)"

Las lámparas servirían para iluminar cada uno de los lados del retablo-baldaquino de Churriguera, colgando de las mismas estructuras de las que, actualmente, penden otras cuatro de nueva factura. Debieron ser piezas que respondían a un diseño habitual de lámparas votivas, formadas por una boya, ornamentada al exterior con las mencionadas cartelas, sustentada por cuatro cadenas que se unen en la parte superior o manípulo.

Además de la descripción, destacamos la repetición del modelo, una cuestión sobre la que es necesario establecer ciertas matizaciones. El encargo se realizó en el año 1729 $\mathrm{y}$, según los registros de fábrica, los autores fueron Carlos Bermúdez y Gerónimo de Campos, plateros vecinos de Ávila, pero no Juan Canales, como se cita en el texto transcrito. En este caso damos mayor veracidad a los datos contenidos en las cuentas, por corresponder al momento en que fueron realizadas las lámparas, en tanto que el inventario es trece años posterior. En cualquier caso, esa referencia nos permite añadir un nombre más a la escasa nómina de plateros abulenses del siglo XVIII.

En diciembre de 1809, el rey José Bonaparte firmó un memorial de las alhajas de plata pertenecientes a la catedral de Ávila que debían entregarse a la Corona, por no considerarlas necesarias para el culto, donde se incluían las cuatro lámparas de plata de la capilla de San Segundo ${ }^{55}$. Unos meses después, en mayo de 1810, se informó sobre la

\footnotetext{
${ }^{55}$ Memorial recogido por Julián Blázquez Chamorro, “El expolio de la platería de las iglesias de Ávila en los años 1808-1810", Cuadernos abulenses, ํo 10 (1988), 11-45.
}

decisión de la Corona, a través del ministro de negocios eclesiásticos, que permitía conservar una de las cuatro lámparas ${ }^{56}$. Como indicábamos, también ha desaparecido la restante.

\section{CONCLUSIONES}

A la luz de los documentos y las obras que hemos incorporado al quehacer de Luis de Torres y Baeza, consideramos que el platero merece situarse entre los maestros destacados de ese momento en la ciudad de Salamanca. Las piezas conservadas manifiestan un lenguaje artístico propio del pleno barroco de la orfebrería salmantina, caracterizado por el contraste de volúmenes y la ornamentación abigarrada, bulbosa y efectista, a través de la conjunción de tarjas con elementos vegetales y frutales, y figuras de ángeles de marcado movimiento.

$\mathrm{Su}$ etapa profesional fue corta, apenas dieciocho años si atendemos a la primera referencia documental que le situaría como maestro, y no muy prolífica, a juzgar por la escasez de piezas vinculables a su nombre y de documentos que le sitúen como autor. En cambio, durante los últimos años de su vida, gozó de un notable reconocimiento en la catedral de Ávila gracias a los contactos profesionales que mantuvo, entre los que destacar su vinculación con el canónigo Amador Merino Malaguilla.

Este personaje fue uno de los principales impulsores artísticos de la seo abulense durante las primeras décadas del siglo XVIII, y habría promocionado a Torres y Baeza como platero de cabecera para los encargos más importantes del cabildo. Las piezas realizadas por él fueron las primeras grandes empresas de platería de cuantas seguirían a lo largo del setecientos, en un periodo de recuperación económica que permitió la paulatina renovación del ajuar litúrgico, en relación con el interés de los capitulares por

${ }^{56}$ ADAV, Sección Archivo Catedralicio, Libro de actas capitulares de 1810, f. 63v. 
cumplir con el decoro y el ornato apropiados para la celebración del culto divino.

La valoración del trabajo de Luis de Torres y Baeza en Ávila, se aprecia en el uso que se dio a sus obras, destinadas a algunas de las celebraciones más importantes, como el Corpus Christi y el Monumento de Jueves Santo; y para alojar las reliquias e iluminar la capilla del santo patrón de la ciudad.

\section{BIBLIOGRAFÍA}

Aterido Fernández, Ángel. El final del Siglo de Oro: la pintura en Madrid en el cambio dinástico 1685-1726. Madrid: CSIC - Coll \& Cortés, 2015.

Blázquez Chamorro, JULIÁN. La platería de la catedral de Ávila. Ávila: Cabildo Catedral de Ávila, 2003.

Blázquez Chamorro, Julián. "El expolio de la platería de las iglesias de Ávila en los años 1808-1810". Cuadernos abulenses, $\mathrm{n}^{\mathrm{o}}$ 10 (1988), 11-45.

Brasas Egido, J. Carlos. "Aportaciones al estudio de la platería barroca española". Boletín del Seminario de Estudios de Arte y Arqueología, no 40-41 (1975), 427-444.

Brasas Egido, J. Carlos. La platería vallisoletana y su difusión. Valladolid: Institución Cultural Simancas, 1981.

Cervera Vera, Luis. "La Capilla de San Segundo en la Catedral de Ávila" Boletín de la Sociedad Española de Excursiones, Año LVI (1959), 181-229.

Cianca, Antonio de. Historia de la vida, invención, milagros y translación de S. Segundo, primero obispo de Ávila. Madrid: Imprenta de Luis Sánchez, 1595.
Gómez-Moreno, Manuel. Catálogo monumental de la provincia de Ávila. Ávila: Institución Gran Duque de Alba, 1983.

Gutiérrez Hernández, Fernando y Lorenzo Martín Sánchez. Platería abulense del Bajo Renacimiento. Pedro Hernández y las mazas del Ayuntamiento de Ávila. Ávila: Ayuntamiento de Ávila, 2003.

Gutiérrez Hernández, Fernando y Lorenzo Martín Sánchez. "Luces y sombras en la platería de la Catedral de Ávila (17001800)". En Estudios de platería. San Eloy 2007, coordinado por Jesús Rivas Carmona, 157-186. Murcia: Universidad de Murcia, 2007.

Pérez Hernández, Manuel. Orfebrería religiosa en la Diócesis de Salamanca. Siglos XV al XIX. Salamanca: Diputación de Salamanca, 1990.

Pérez Hernández, Manuel. "Sobre la interdisciplinariedad de las artes. Manuel García Crespo y el barroco salmantino". En Estudios de platería. San Eloy 2007, coordinado por Jesús Rivas Carmona, 271-297. Murcia: Universidad de Murcia, 2007.

Pérez Hernández, Manuel. "El tesoro de la catedral de Ávila. Liturgia y magnificencia". En La catedral de Ávila. Nueve siglos de historia y arte, coordinado por René Jesús Payo Hernanz y Jesús M. Parrado del Olmo, 427-476. Burgos: Promecal, 2014.

Sánchez Sánchez, David. "El platero abulense Lucas Hernández (c. 1547-1593). Obra y datos biográficos a partir de su testamento". En Estudios de platería. San Eloy 2018, coordinado por Jesús Rivas Carmona e Ignacio J. García Zapata, 491-507. Murcia: Universidad de Murcia, 2018. 